\title{
Optimization Approach for Solvent Extraction Process of Oily Contaminated Soil with Addition of Biosurfactant
}

\author{
Lely Fitriyani ${ }^{1,4,+\oplus} \cdot$ Edwan Kardena $^{2} \cdot$ Sukandar $^{1} \cdot$ Qomarudin Helmy $^{2,3 \oplus}$ \\ ${ }^{1}$ Environmental Engineering Department, Institute Technology of Bandung, Bandung, Indonesia \\ ${ }^{2}$ Water and Wastewater Engineering Research Group, Institute Technology of Bandung, Bandung, Indonesia \\ ${ }^{3}$ Bioscience and Biotechnology Research Center, Institute Technology of Bandung, Bandung, Indonesia \\ ${ }^{4}$ PT. Prasadha Pamunah Limbah Industri, Nambo, Jawa Barat, Indonesia
}

(Received November 19, 2020; Revised January 11, 2021; Accepted January 22, 2021)

Objectives: Solvent extraction is a process in which not only enable to reduce oil contaminant from soil residue, but also capable to recover oil from soil matrix of oily contaminated soil which has opportunity to be reutilized. Optimization process has been simulated by previous studies related to type and dosage of solvents, variances of temperature, additional of surfactants, and other related parameters to increase oil removal from oily contaminated soil. This study seeks an approach of optimization for solvent extraction process to oily contaminated solid waste by conducting statistical analysis into laboratory experimentation from perspective of Total Petroleum Hydrocarbon (TPH) removal.

Method: Biosurfactant became single extractors for multistage extraction process and also combined with other solvents which are acetone and toluene. Mixing method that utilized during the study was combination between horizontal shaking at $150 \mathrm{rpm}$ in $15 \mathrm{~min}$ duration and centrifugation force at $1,570 \mathrm{~g}$ in $10 \mathrm{~min}$ duration. Statistical analysis were conducted to seek its multiple regression.

Result: Study describing biosurfactant performance single extractor by using multistage extraction process achieve $77 \%$ TPH removal, while combination of biosurfactant and solvent extraction by using toluene and acetone also capable to increase TPH removal 7\% higher from original performance of both toluene and acetone at solvent extraction.

Conclusion: Surfactant and solvents combination is promising to improve TPH removal, while statistics analysis that implemented to observed extraction process has possibility to be used for engineering higher efficiency of extraction process.

Keywords : Biosurfactant, Contaminated Soil, Oil Sludge, Soil Washing, Solvent Extraction, TPH 


\section{Introduction}

Soil remediation attracts a lot of interest due to large volume of contaminated soil produced years behind, yet it keeps continuing to be produced up till now. Its generation would be proportionally related to oil production and the safety and environmental awareness related to oil production. Physical and chemical process may do faster treatment processes that has becoming well known as its major benefit, while biological processes are able to handle bulk of waste in certain period with lower risk to the environment.

As part of physical and chemical process, solvent extraction has been also preferred for its high recovery rate on oil reutilization. Optimization has been studied to gain better performance from the side of recovery, however very few studies report the quality of soil after treatment. Utilization of biosurfactant for solvent extraction has been reported by Zhang et al. ${ }^{1)}$ that with optimum formulation of biosurfactant, oil recovery of $74.55 \%$ was obtained when washing at $20^{\circ} \mathrm{C}$ and $200 \mathrm{rpm}$ for one hour. Helmy et al. ${ }^{2)}$ in 2014 previously also conduct some studies related to the usage of biosurfactant and reported that usage of biosurfactant from Burkholderia sp. were able to enhance the rate of biodegradation efficiency on removing petroleum hydrocarbon up to $65 \%$.

Solvent extraction process essentially is an adsorptiondesorption process of oil between the solid and liquid phases. ${ }^{3)}$ Biceroglu ${ }^{4)}$ in 1994 has been used intermediate hydrocarbon source to be able to extract oil sludge from refinery storage to become lighter hydrocarbon at several stages of temperature. El Naggar et al. ${ }^{5)}$ studied the usage of some solvents such as naphthalene, kerosene cut, n-heptane, toluene and some other solvents. Zubaidy and Abuelnasr ${ }^{6}$ in 2010 made comparative study related to the effect of some organic solvents such as methyl ethyl keton (MEK) and liquefied petroleum gas condensate (LPGC). The following Table 1 will describe summary of solvent extraction studies for oily waste as referred by this study.

Biosurfactant has its unique property of reducing the surface and interfacial tensions using the similar mechanisms as chemical surfactants. During the experiments some solvents has been selected to be implemented at solvent extraction process, the addition of biosurfactant was also observed to understand its contribution for solvent extraction process. This study also conducts statistics analysis to give approach for optimizing process in larger scale. Random sampling method was utilized and multiple regression analysis were conducted for giving closer approach for set of experiments.

\section{Material and Method}

\subsection{Biosurfactant and EP24}

As part of characterization process for biosurfactants, Emulsification index (EP24) is determined by performing centrifugation at $13,000 \mathrm{rpm}$ to separate biosurfactant from microorganism cells yielded a biosurfactant cell free. ${ }^{10)}$ Biosurfactant and crude oil in ratio 1:1 was agitated for $2 \mathrm{~min}$ then stabilized for $24 \mathrm{~h}$. Emulsification index (\%) determined by measuring the column height of emulsified oil against its total height multiplied by 100 .

Selected biosurfactant of the experiments produced by Bioscience and Biotechnology laboratory at Institute Technology of Bandung. Selected isolate of Burkholderia sp._PAU02 has capability to reduce surface tension to the point of 47.0 dyne/cm and emulsification index EP24 of $84 \%$. Solvent extraction process and analysis of parameters have been conducted at PPLi laboratory in Cileungsi, Bogor. TPH content was analyzed referring to USEPA 8440 method about total recoverable petroleum hydrocarbons by using infrared spectrophotometry, while metal elements for solid were measured using inductively Coupled Plasma (ICP) analysis

Table 1. Solvent extraction research for oily contaminated solid waste.

\begin{tabular}{|c|c|c|c|c|}
\hline Year & Name & Method & Solvent & Oil removal \\
\hline 2005 & Gazineu et al. ${ }^{7)}$ & Solvent extraction & Turpentine & $\begin{array}{c}13-53 \% \text { oil from original oil } \\
\text { sludge mass }\end{array}$ \\
\hline 2006 & Taiwo and Otolorin ${ }^{8)}$ & Solvent extraction & Hexane and Xylene & $67.50 \%$ \\
\hline 2010 & Zubaidy and Abouelnasr ${ }^{6)}$ & Solvent extraction & $\begin{array}{c}\text { Methyl ethyl ketone (MEK) and liquefied } \\
\text { petroleum gas condensate (LPGC) }\end{array}$ & $\begin{array}{l}39 \% \text { for MEK and } \\
32 \% \text { for LPGC }\end{array}$ \\
\hline 2010 & El Naggar et al. ${ }^{5)}$ & Solvent extraction & Toluene & $75.94 \%$ \\
\hline 2015 & Hu et al. ${ }^{9)}$ & Solvent extraction + Freeze thaw & MEK and Ethyl Acetate (EA) & $\begin{array}{l}40 \% \text { for MEK and } \\
60 \% \text { for EA }\end{array}$ \\
\hline
\end{tabular}


base on USEPA 3050 B Method by conducting acid digestion method using $\mathrm{HNO}_{3}$ and $\mathrm{H}_{2} \mathrm{O}_{2}$. Solvent extraction method conducted by running horizontal shaker equal to $150 \mathrm{rpm}$ for $15 \mathrm{~min}$ then continued by centrifugation SETA Oil Test Centrifuge at 1,000 rpm $(1,570 \mathrm{~g})$ for $10 \mathrm{~min}$ duration. Extract of aliquot and solid was separated by using vacuum filtration method using Whatman series CAT-1825-047 that has $47 \mathrm{~mm}$ of diameter.

\subsection{TPH Removal}

TPH removal (Ro) from the oily contaminated soil and the oil concentration in the solvent (Co) were calculated as mentioned in the following Eq. 1 and Eq. 2:

$$
\begin{aligned}
& \mathrm{Ro}=((\ulcorner 0-\ulcorner 10)) /(\ulcorner 0) \\
& \mathrm{Co}=((\ulcorner 0-\ulcorner 10)) /(\mathrm{m} / \mathrm{V})
\end{aligned}
$$

Where $\left\ulcorner_{0}\right.$ and $\left\ulcorner_{10}\right.$ are the initial and residue oil contents that measured as Total Petroleum Hydrocarbon (TPH) in the contaminated soil $(\mathrm{g} / \mathrm{g})$, respectively, $\mathrm{m}$ is the mass of soil $(\mathrm{g})$ and $\mathrm{V}$ is the solvent volume $(\mathrm{mL})$.

\subsection{Preparation of Sample}

The sample was stored in a jar at $25^{\circ} \mathrm{C}$. Aliquot of 1,000 grams of contaminated soil were collected in a tray. Sample were dried by using open air for three days to minimize moisture content for further experiments. After drying the solid sample was mixed evenly so to ensure the homogeneity. Homogenous sample would be further observed as the following experimental treatment procedure that listed at Table 2.

\section{Result and Discussion}

This study initiated with examining characteristics of samples that would be treated by using several types of treatments which are mentioned above. Samples then randomly arranged to be treated for selected treatment. Control treatment was conducted using distilled water as blank reference for entire selected treatments and combinations.

\subsection{Raw Waste Characteristics}

There are two types of waste that has been observed during the study, the following Table 3 shows the result of waste characteristics of waste type A that has been observed during the study. The average number would be considered as TPH concentration of raw waste.

\subsection{Multistage Biosurfactant Extraction}

First stage of biosurfactant extraction to waste type A conducted with ratio $1: 1$ by using the sequence of $15 \mathrm{~min}$ shaking then continued with $10 \mathrm{~min}$ centrifugation at room temperature as mentioned at Table 1 was able to provide TPH removal $28.5 \%$. Second stage implemented provided TPH removal up to $56.1 \%$, while third and fourth stage of extraction increase provided result of TPH removal $71.6 \%$ and $77.4 \%$ respectively.

Observation has been also conducted to oily contaminated soil from contaminated soil from oil drilling base mud contamination which containing average TPH $17.89 \%$ named as waste type $\mathrm{B}$ in this experiment. Biosurfactant extraction also implemented to the waste type B for four stages of extraction as it has been implemented before to waste type

\begin{tabular}{|c|c|c|}
\hline No & Type & Duration \\
\hline 1 & Biosurfactant & $\begin{array}{l}15 \text { min shaker for biosurfactant at } 150 \mathrm{rpm}, 10 \mathrm{~min} \text { centrifugation at } 1,000 \mathrm{rpm} . \\
\text { Ratio soil : biosurfactant is } 1: 1\end{array}$ \\
\hline 2 & Solvent & 15 min shaker for solvent at $150 \mathrm{rpm}, 10 \mathrm{~min}$ centrifugation at 1,000 rpm \\
\hline 3 & Biosurfactant + Solvent & $\begin{array}{l}15 \text { min shaker for biosurfactant at } 150 \mathrm{rpm}, 15 \mathrm{~min} \text { shaker for solvent at } 150 \mathrm{rpm} \text {, } \\
\qquad 10 \mathrm{~min} \text { centrifugation at 1,000 rpm }\end{array}$ \\
\hline
\end{tabular}

Table 2. Sequence of experimental procedure.

\begin{tabular}{|c|c|c|c|}
\hline Parameter & $\begin{array}{c}\text { A } \\
\text { Jawa }\end{array}$ & Sumatera & Unit \\
\hline $\mathrm{pH}$ & 8.7 & 8.3 & - \\
\hline Moisture & 13.3 & 11.6 & $\%$ \\
\hline Density & 1.1 & 1.2 & $\mathrm{~g} / \mathrm{m}^{3}$ \\
\hline
\end{tabular}

Table 3. Raw contaminated soil characteristics. 
A which has typical sandy soil. In Table 3 characteristics of waste type B was also described based on its key parameters.

Waste type B has clay characteristics and having higher TPH content compare waste type A. Raw waste that has $17.86 \%$ and obtain result of TPH removal average $14-17 \%$ of every stage of biosurfactant extraction. The entire total four stages of extraction process gave $49.53 \%$ of TPH removal. The following Fig. 1 below present complete observation result for four stages of biosurfactant extraction for both type A and type B soil waste.

Analysis of Gas Chromatography-Flame Ionization Detector (GC-FID) also conducted for raw waste type A and every stage of treatment result. A comparison between raw waste hydrocarbon composition prior and after treatment shall give better understanding for obtaining result. The following Fig. 2 and Fig. 3 gave description of raw waste type A and result after bio-surfactant multistage extraction process.

Chromatogram above presented some peaks around C8-C29. Most peaks are available between $\mathrm{C} 20-\mathrm{C} 25$. This is giving verification for source that coming from contamination of crude oil to sandy soil at the shore of an offshore platform located nearby. In the Fig. 3 provided chromatogram result after 4 stages extraction has been conducted, while by also referring chromatograms comparison at Fig. S1 until Fig. S3 the comparison of chromatograms for each of four stages biosurfactant extraction giving confirmation that at the latest stage of extraction, hydrocarbon composition reduced both in concentration and complexities.

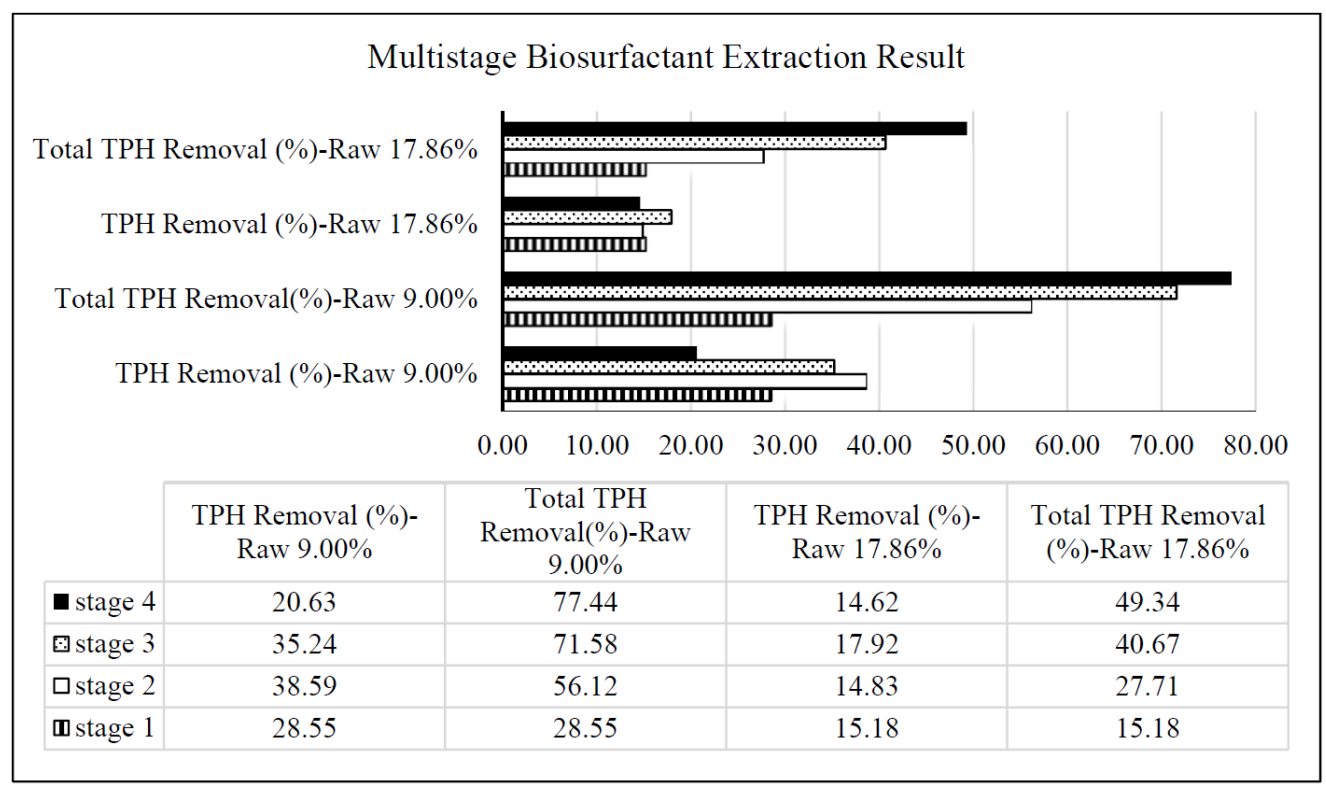

Fig. 1. Multistage biosurfactant extraction result.

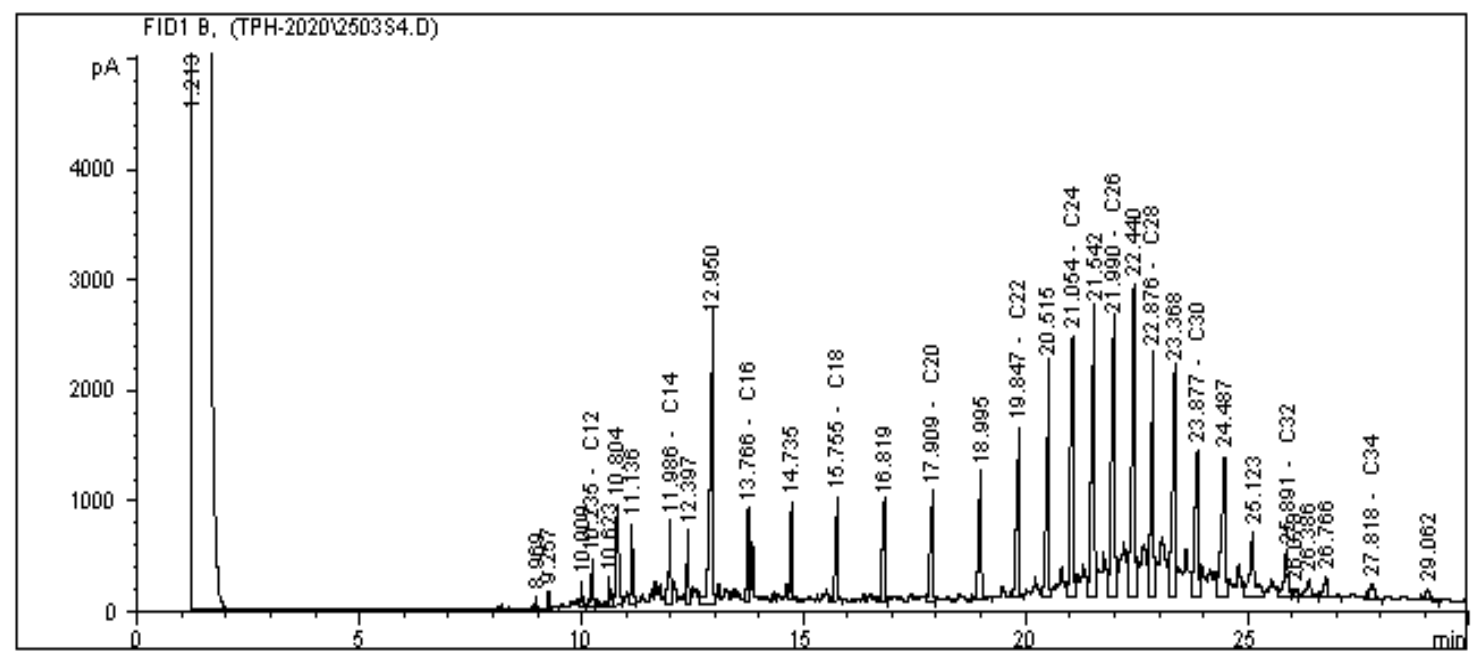

Fig. 2. Chromatogram of raw waste type $A$. 


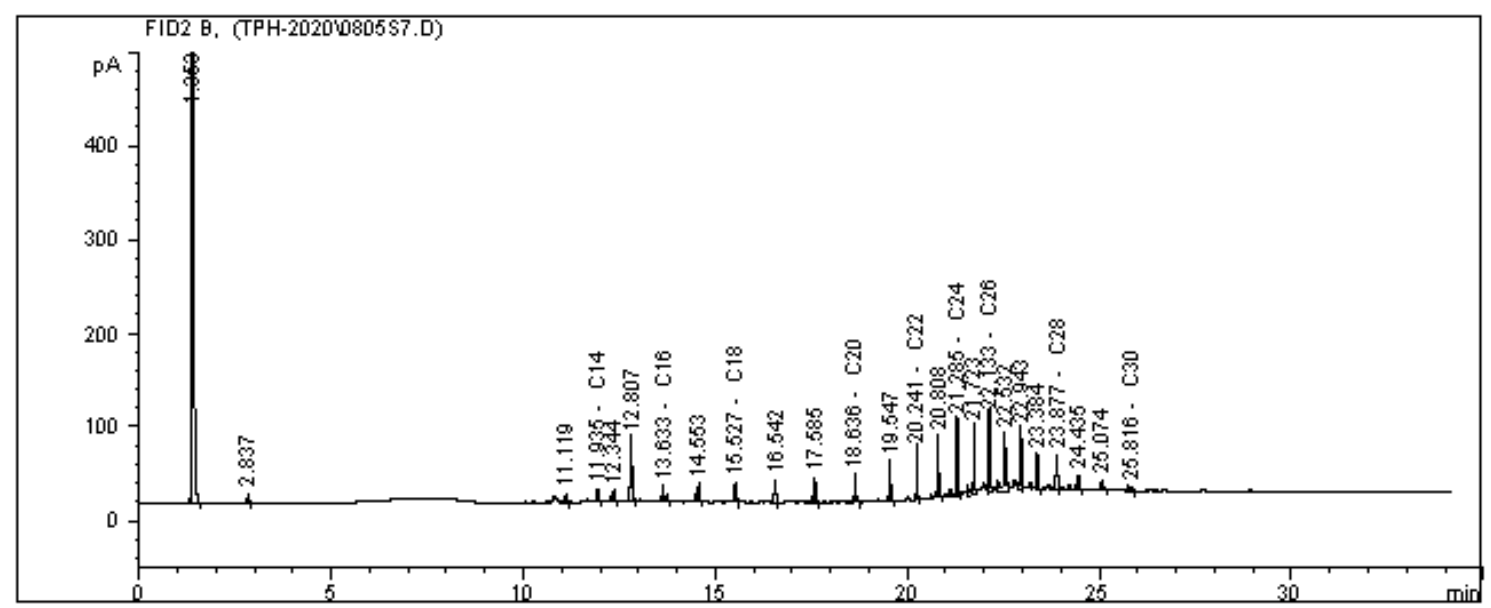

Fig. 3. Chromatogram of fourth stage of biosurfactant extraction waste type A.

A comparison for both biosurfactant extraction process has been conducted to have better understanding regarding the performance of biosurfactant during the study. Biosurfactant extraction that involve waste type A which utilized sandy soil, having higher moisture content, and having lower TPH has higher total removal of TPH. Waste type B which has typical clay soil, having moisture content $13.3 \%$ and having ТPH $17.86 \%$ has lower TPH removal rate for every stage of extraction and for total obtained recovery rate.

\subsection{Multistage Biosurfactant Extraction Model}

Influence of biosurfactant in for TPH removal of oily contaminated soil by using solvent extraction method has been observed at the following set of experiment at Table S1. During the experiment there are two types of waste that has been observed. Both type A and type B performed multistage extraction process that involving selected biosurfactant. Comparison between biosurfactant and solid was 1:1 for every stage of solvent extraction process.

Observing the experiments result statistically by utilizing SPSS analysis tool to run multiple regression, the experimental result came to an approach as stated below at the following model stated at Eq. 3:

$$
\text { Ro }=49.319-1.706 \times\ulcorner 0-1.28 \times S t
$$

Where, Ro : TPH Removal (\%)

$$
\begin{aligned}
&\ulcorner 0 \text { : Initial TPH (\%) } \\
& \text { St }: \text { Extraction stage }
\end{aligned}
$$

Based on model above Initial TPH and extraction stage having contribution $49.78 \%$ and $50.22 \%$ respectively. Those formulations and values of contribution factor giving information that degree of TPH removal is proportionally related to the initial TPH concentration of contaminated soil or waste and level of extraction process. Both factors giving lower removal along with higher TPH and higher level of extraction process.

\subsection{Combination of Biosurfactant at Solvent Extraction Model}

Sample that has been examined at the experiment of combination between biosurfactant and solvents involving toluene and acetone was sample B Sumatera that has TPH $17.86 \%$. In the following Table S2, there are 16 batches of treatment that has been conducted to seek the impact of biosurfactant along with other solvent extraction parameters at solvent extraction process.

Based on result that obtained during the experiment by using statistical method using SPSS for multi-regression model. an approach to for removal of TPH is introduced. By using model that stated at Eq. 4 and the selection of independent variables that giving contribution, while the other parameter considered ceteris paribus then make value of result absolute the result in Table S3 contribution factor of each variable is described.

$$
\begin{aligned}
\text { Ro }= & 71.565-27.477 \mathrm{~b} / \mathrm{s}-33.828 \times \mathrm{s} / \mathrm{sol} \\
& +28.828 \times S o t+0.298 \times T
\end{aligned}
$$

Where, Ro : TPH Removal (\%)

$$
\begin{aligned}
\ulcorner 0 & : \text { Initial TPH (\%) } \\
\text { St } & : \text { Extraction stage } \\
\text { Sot } & : \text { Solvent type } \\
\mathrm{T} & : \text { Temperature }
\end{aligned}
$$

Comparing model $\mathrm{B}$ with experiments that has been 
conducted by Zhang et al. ${ }^{1)}$ in 2012 , this giving confirmation into his experimental graph that showing even solid to solvent varied in to solvent extraction process that using biosurfactant, the variances itself did not giving significant impact. Other parameters such as solvent type and temperature would rather give more impact to TPH removal.

\subsection{Regression Analysis Test}

There are four assumption that needed to be fulfilled while performing regression analysis. Those are 1) residue scattered normal or normal distribution, 2) residues are homogenous uniform or heteroscedastic, 3) multicollinearity or there is no correlation between independent variables. In the other hand it shall also perform regression 4) model test $\left.\left(R^{2}\right), 5\right) \mathrm{f}$ test ANOVA, and 6) $t$ test. Assumption test conducted for both models and the following are results of those implemented tests.

\subsubsection{Normal Distribution Test}

Normal distribution test having objective to observed normality of data distribution. Kosmogorov-Smirnov normality test has been utilized and giving the result at Table \$4 for both models. According to output from statistical analysis Asymptotic Significance (2-tailed) of both models have values more than 0.05 . Therefore, it can be concluded that data distributed normally.

\subsubsection{Homoscedastic Test}

Analysis result of homoscedastic test that has been conducted and described at TableS5 also be able to explain that for model A homoscedasticity occurred at TPH raw variable other than that all parameters showed their non-homoscedasticity.

\subsubsection{Multicollinearity Test}

Multicollinearity test used to find there is linearity in between independent variables at the regression model. Multicollinearity would be able to be detected by Variance Inflation Factors (VIF). If VIF $<10$, it indicates there is no multicollinearity occurred, while in the other hand if VIF $>$ 10 multicollinearity shall occur. According output of statistical analysis, it has been observed that VIF values for all variable at both models are less than 10 . Therefore, assumption that all models have no multicollinearity is fulfilled.

\subsection{4. $\left(R^{2}\right)$ Test}

$\mathrm{R}$ Square value Adjusted on SPSS explained percentage of compatibility for multi-regression model. In the other word it shall able to show variables independent giving its function to dependent variable. At Table S7, described $\mathrm{R}^{2}$ adjusted values from each model $\mathrm{A}$ has $61.5 \% \mathrm{R}$ square value, while model $\mathrm{B}$ has $65.3 \% \mathrm{R}$ square value.

\subsubsection{F Test (ANOVA)}

$F$ test has objective to examine influence of independent variable simultaneously that showed at "Sig." Column in ANOVA table. Hypothesis that referred are:

$\mathrm{H}_{0}$ : All variables not significantly related to dependent variable

$\mathrm{H}_{1}$ : All variables significantly related to dependent variable While test Criteria:

- Sig. value $>0.05 \mathrm{H}_{0}$ rejected

- Sig. value $<0.05 \mathrm{H}_{0}$ accepted

According to values of $\mathrm{F}$ test at ANOVA test result table, it is indicated that $\mathrm{H}_{0}$ accepted.

\subsubsection{T Test}

$\mathrm{T}$ test utilized to examine influence of each independent variables partially to the dependent variable. If Sig. $<0.05$, $\mathrm{H}_{0}$ rejected. Hypothesis that are referred:

$\mathrm{H}_{0}$ : Independent variable not significantly influencing TPH removal

$\mathrm{H}_{1}$ : Independent variable significantly influencing TPH removal

According to statistical analysis that has been conducted both models having independent variable that not significantly influencing ТPH removal are extraction stage, temperatures, and solid to solvent ratio.

\subsection{TCLP Analysis for Residue of Biosurfactant Extraction}

TCLP analysis also conducted to the residual treated contaminated soil to study about its metal leaching properties of residual treatment process for multistage of biosurfactant extraction. Heavy metal key parameters were analyzed to check its contribution on leaching factor for its possibility to be final disposed at controlled landfill. The following Table 4 provided data that all heavy metal parameters having lower concentration compare to required parameters that regulated by government of Indonesia PP 101 year 2014 so that it can be treated at non-hazardous waste landfill. Further discussion and study shall also be conducted to have more data related to these possibilities. 
Table 4. Metal analysis of waste type $A$ residue.

\begin{tabular}{|c|c|c|c|c|}
\hline & $\begin{array}{l}\text { Limit value TCLP-A } \\
\text { (PP101/2014) }\end{array}$ & $\begin{array}{l}\text { Limit value TCLP-B } \\
\text { (PP101/2014) }\end{array}$ & $\begin{array}{c}\text { TCLP of } \\
\text { Raw waste type A }\end{array}$ & $\begin{array}{c}\text { TCLP of } \\
\text { Residue waste type } \mathrm{A}\end{array}$ \\
\hline Metal element & Concentration (mg/L) & Concentration (mg/L) & Concentration (mg/L) & Concentration (mg/L) \\
\hline $\mathrm{Sb}$ & 6 & 1 & 0 & 0.0203 \\
\hline As & 3 & 0.5 & 0.131 & 0 \\
\hline $\mathrm{Ba}$ & 210 & 35 & 0.6145 & 0.2065 \\
\hline $\mathrm{Be}$ & 4 & 0.5 & 0.0002 & 0 \\
\hline B & 150 & 25 & 0.8340 & 0.3577 \\
\hline $\mathrm{Cd}$ & 0.9 & 0.15 & 0 & 0.0796 \\
\hline $\mathrm{Cr}$ & 15 & 2.5 & 0 & 0.0545 \\
\hline $\mathrm{Cu}$ & 60 & 10 & 0.0389 & 0.0279 \\
\hline $\mathrm{Pb}$ & 3 & 0.5 & 0.315 & 0 \\
\hline $\mathrm{Hg}$ & 0.3 & 0.05 & 0 & 0.0091 \\
\hline Mo & 21 & 3.5 & 0 & 0.0176 \\
\hline $\mathrm{Ni}$ & 21 & 3.5 & 0.0038 & 0 \\
\hline Se & 3 & 0.5 & 0 & 0.0942 \\
\hline $\mathrm{Ag}$ & 40 & 5 & 0.0094 & 0.0742 \\
\hline $\mathrm{Zn}$ & 300 & 50 & 0.018 & 0.0019 \\
\hline
\end{tabular}

\section{Conclusion}

Application of solvent extraction has been occurred for years, yet the equipment related to the centrifugation process and its supporting equipment for pre-treatment has been available for years. Control of temperatures and mixing condition were also has been applied. Solvent extraction may give better optimum condition for oil recovery, however the optimization of solvent or biosurfactant recycling shall also be considered.

Biosurfactant extraction may give an opportunity to have better TPH removal by using multistage process, however this treatment shall give better alternative to the have natural biodegradative agent for extraction process of oily contaminated soil.

Multistage biosurfactant extraction implementation achieved TPH removal up to $77.44 \%$ for contaminated waste that has original ТPH $9.00 \%$, while achieve $49.34 \%$ of TPH removal for contaminated soil that has $17.89 \%$ original TPH.

Based on approached model it all parameters that involved at solvent extraction such as type of soil, moisture has most significant impact for TPH removal. By using the approached model, it shall also perform optimization for TPH removal due to adjustment of parameters referring the model.

Combination of biosurfactant at solvent extraction process is a method that can be implemented as an alternative to remove TPH as pollutant at the contaminated soil and also an option for recycling to increase longer utilization of oil for any other applicable purposes. Parameters that significantly impacting TPH removal are solvent type and temperature.

Residual result for TPH, Chromatogram, Metal Content, TCLP for metal also indicate solvent extraction process may give opportunity for the residue to be used for other purposes and or having any further bioremediation process.

\section{References}

1. J. Zhang, J. Li, R. W. Thring, X. Hu, X. Song, Oil recovery from refinery oily sludge via ultrasound and freeze/thaw, J. Hazard. Mater., 203-204, 195-203(2012).

2. Q. Helmy, E. Kardena, N. Funamizu, Wisjnuprapto, Strategies toward commercial scale of biosurfactant production as potential substitute for it's chemically counterparts, Int. J. Biotechnol., 12(1/2), 66-86(2011).

3. J. Liang, L. Zhao, N. Du, H. Li, W. Hou, Solid effect in solvent extraction treatment of pre-treated oily sludge, Sep. Purif. Technol., 130, 28-33(2014).

4. O. Bicoreglu, Rendering Oily Waste Land Treatable or Usable, U.S. Patent 5(1994).

5. A. Y. El Naggar, E. A. Saad, A. T. Kandil, H. O. Elmoher, Petroleum cuts as solvent extractor for oil recovery from petroleum sludge, J. Pet. Technol. Altern. Fuels, 1(1), 10-19 (2010).

6. E. A. H. Zubaidy, D. M. Abouelnasr, Fuel recovery from waste oily sludge using solvent extraction, Process Saf. Environ. Prot., 88(5), 318-326(2010).

7. M. H. P. Gazineu, A. A. de Araujo, Y. B. Brandao, C. A. 
Hazin, J. M. O. Godoy, Radioactivity concentration in liquid and solid phases of scale and sludge generated in the petroleum industry, J. Environ. Radioact., 81(1), 47-54(2005).

8. E. A. Taiwo, J. A. Otolorin, Oil recovery from petroleum sludge by solvent extraction, Pet. Sci. Technol., 27(8), 836-844(2009).

9. G. Hu, J. Li, H. Hou, A combination of solvent extraction and freeze thaw for oil recovery from petroleum refinery wastewater treatment pond sludge, J. Hazard. Mater., 283, 832-840(2015).

10. D. M. Arsyah, E. Kardena, Q. Helmy, Characterization of biosurfactant produced by petrofilic bacteria isolated from hydrocarbon impacted soil and its potential application in bioremediation, IOP Conf. Ser.: Earth Environ. Sci., 106, 012101(2018).

\section{Declaration of Competing Interest}

The authors declare that they have no known competing financial interests or personal relationships that could have appeared to influence the work reported in this paper.

\section{Authors and Contribution Statement}

\section{Lely Fitriyani}

Environmental Engineering Department, Institute Technology of Bandung, Bandung, Indonesia, PT. Prasadha Pamunah Limbah Industri, Nambo, Jawa Barat, Indonesia, Ph.D. Student, ORCiD(1) 0000-0002-3164-6344: Data curation, Data analysis, Writing original draft.

\section{Edwan Kardena}

Water and Wastewater Engineering Research Group, Institute Technology of Bandung, Bandung, Indonesia, Associate Professor: Project administration.

\section{Sukandar}

Environmental Engineering Department, Institute Technology of Bandung, Bandung, Indonesia, Associate Professor: Project administration.

\section{Qomarudin Helmy}

Water and Wastewater Engineering Research Group, Institute Technology of Bandung, Bandung, Indonesia, Bioscience and Biotechnology Research Center, Institute Technology of Bandung, Bandung, Indonesia, Assistant Professor, ORCiD(C) 0000-00033972-8261: Resources, Writing - review and editing. 